\title{
Profissionalismo e diferença de gênero na magistratura paulista
}

\author{
Professionalism and gender difference in \\ São Paulo's magistrature
}

Maria da Gloria Bonelli*

\begin{abstract}
Resumo: Este artigo analisa as mudanças na composição de gênero da magistratura paulista, que ocorreram simultaneamente ao processo de reforma do Judiciário. Argumenta que o tribunal usou de estratégias de recrutamento e de controle para se manter como carreira pública de elite. Ao enfrentar um ambiente externo que pressionava por reformas e um ambiente interno mais heterogêneo, deu centralidade à postura profissional, procurando homogeneizar a diferença através da identificação com "ser magistrado(a)". A diferença é conceituada e sugerida às formas como ela é interpretada na magistratura. Destaca-se a diferença como subjetividade, parte da esfera íntima, vindo a público o compartilhamento de uma corporalidade que distingue o grupo e produz sua eficácia simbólica. O artigo baseia-se em 20 entrevistas semiestruturadas realizadas com magistrados (as) para o projeto Profissionalismo e gênero nas carreiras jurídicas, financiado pelo CNPq, além de dados quantitativos e fontes documentais.

Palavras-chave: Profissões, magistratura, diferença, gênero
\end{abstract}

\begin{abstract}
This article focuses on the changes in the gender composition of the São Paulo magistrature, which occurred simultaneously to the judicial reform process. The argument is that the Appellate Court adopted strategies of judicial recruitment and control to maintain itself as an elite public career. The Tribunal de Justiça de São Paulo had to deal with an external environment claiming for the judicial reform as well as a more heterogeneous internal environment. In this context, it gave centrality to the professional posture, searching to restore homogeneity through the collective identification of magistrate. The article conceptualizes the difference and suggests forms of how it is interpretated within the magistrature. The difference stands out as subjectivity, as part of the interiority, presenting a shared corporality that distinguishes the group and that produces its symbolic efficacy. The empiric base for the study is the data gathered by the project Professionalism and gender in the legal careers, sponsored by $\mathrm{CNPq}$, with quantitative data, 20 qualitative interviews, and documental sources.
\end{abstract}

Keywords: Professions, magistrates, difference, gender

* Professora titular da Universidade Federal de São Carlos, atuando no Programa de PósGraduação em Sociologia. <gbonelli@uol.com.br>.

\begin{tabular}{|l|l|l|l|l|l|}
\hline Civitas & Porto Alegre & v. 10 & n. 2 & p. 270-292 & maio-ago. 2010 \\
\hline
\end{tabular}




\section{Introdução: O Tribunal de Justiça de São Paulo em um contexto de mudanças (1990-2010)}

O Tribunal de Justiça de São Paulo (TJSP) está entre as instituições jurídicas que mais cedo caminharam na consolidação de um tipo de profissionalismo moldado a uma organização pública de elite. As garantias da carreira, o ingresso por concurso com a seleção dos pares, a padronização dos critérios de promoção, o controle interno pela corregedoria, a escolha da cúpula do tribunal pelos membros da segunda instância, e a demarcação das fronteiras entre política e profissão deram solidez à autonomia da magistratura.

O ideário que acompanhou esta construção enfatizou a independência judicial e a neutralidade dessa expertise, alcançando elevado prestígio social e autoridade cultural, na qual os magistrados, ao dizerem o Direito, dizem para a sociedade o que é direito nos mais variados campos da vida social. Embora, em geral, os juízes usufruam de um alto status, registram-se diferenças significativas nos resultados alcançados na construção do poder judicial e na autonomia profissional. O Tribunal de Justiça de São Paulo liderou este processo no Brasil. Seus membros se orgulham de ser parte da magistratura paulista, o que é maior e mais duradouro do que ser juiz(a). Mesmo sendo críticos das "mazelas do Judiciário", a grande maioria busca agir de forma a não enfrentar problemas de conduta que possam comprometer a trajetória da carreira e o pertencimento institucional.

A preocupação com a preservação de tal posição construída ao longo do século XX revela-se no controle sobre o processo seletivo e sobre a composição da cúpula do tribunal. Apenas os desembargadores votam na escolha da cúpula do TJSP e só os três mais antigos membros da segunda instância podem se candidatar à presidência do tribunal. Em outras carreiras jurídicas públicas a eleição da cúpula é feita por todos os membros da carreira. No caso dos concursos públicos, várias carreiras jurídicas dispensam a entrevista como parte do processo seletivo, limitando as fases eliminatórias às provas de conteúdo. O TJSP, além do exame escrito, do exame oral, da avaliação psicológica e de saúde e das cartas de informação, realiza também uma entrevista pessoal após a prova oral pública, e toma tal entrevista como auxiliar na decisão da banca ${ }^{1}$. Neste aspecto o recato dos(as) candidatos(as) padroniza a postura, evitando a diferença corporificada, conduta que passará por ressignificações com o vitaliciamento do juiz.

Sobre os concursos para ingresso na magistratura estadual paulista, a progressão na carreira e o funcionamento do tribunal, ver Cardia (1998) www.nevusp.org, pesquisas concluídas. 
A dimensão subjetiva do processo de seleção é acompanhada do anedotário que circula no mundo jurídico e na própria magistratura, sobre o controle que as bancas dos concursos detêm, barrando a entrada dos candidatos vistos como diferentes na entrevista pessoal. Até a década de 1960, falava-se na barreira étnica, nas dificuldades de acesso dos descendentes de imigrantes que não tinham "berço". No início dos anos 1990, já com a expansão dos cursos superiores de Direito e o aumento da participação feminina no mercado de trabalho jurídico, foi a vez de se destacar a barreira para o ingresso das mulheres na magistratura paulista.

Em 1993, o TJSP contava com 1372 magistrados, sendo 10\% de mulheres. No início de 2010 tinha 2372 magistrados, sendo 745 (31\%) mulheres.

Na segunda instância, em 1993 não havia nenhuma mulher, chegando a 2010 com 13 desembargadoras, sendo 9 delas do quinto constitucional ${ }^{2}$ vindas do Ministério Público (MP) e da Ordem dos Advogados do Brasil de São Paulo (OAB-SP). Quatro desembargadoras haviam progredido na carreira até o pleno do tribunal. O total de vagas de desembargadores no TJSP é de 360. Quando os dados foram coletados ${ }^{3}, 352$ cargos estavam preenchidos, e a participação feminina correspondia a menos de $4 \%$.

A primeira instância da carreira divide-se em quatro níveis de progressão: juiz(a) substituto (a), entrância inicial, entrância intermediária e entrância final. A entrância intermediária é a que apresenta uma porcentagem maior de magistradas (47\%) no judiciário paulista, valor que se reduz um pouco na composição da entrância inicial $(41 \%)$ e das juízas substitutas $(45 \%)$. A entrância final conta com $26 \%$ de magistradas.

O trabalho de campo buscou selecionar magistrados(as) nas listas nominais do TJSP, em diferentes momentos da carreira. As 20 entrevistas foram realizadas a partir de um roteiro semi-estruturado. Do total de magistrados(as), 6 atuavam na capital e os demais em cidades do interior, 9 são homens sendo 3 desembargadores; das 11 mulheres, 1 era desembargadora. Há uma variação na faixa etária, com a maioria entre 30 e 40 anos.

A magistratura paulista é uma carreira pública de elite, que viu seu prestígio atingido pelo debate sobre a reforma do Poder Judiciário nos anos 1990-2000, visando dar-lhe maior eficiência, previsibilidade das decisões, desburocratização do funcionamento e acesso à justiça. As iniciativas reformistas vieram das pressões do ambiente externo: do Executivo, do

\footnotetext{
2 A carreira da magistratura divide-se em duas instâncias, com os juízes atuando na primeira e os desembargadores na segunda. $\mathrm{O}$ acesso à segunda instância se dá pela progressão interna, ou pelo quinto constitucional, que reserva $20 \%$ das vagas para o MP $(10 \%)$ e para $\mathrm{OAB}(10 \%)$, que fazem suas indicações.

3 Dados coletados no site do TJSP, www.tj.sp.gov.br, em 18/1/2010.
} 
Legislativo, de agências internacionais (como o Banco Mundial) e da mídia. Internamente, predominou a resistência a aspectos centrais da reforma judiciária, que é aprovada em 20044. Foi no momento mais vulnerável do tribunal que a ampliação do ingresso de juízas ganhou volume.

O prestígio e a elitização do tribunal foram arranhados nesse processo, e a renovação da magistratura trouxe a preocupação da cúpula em resguardar a posição elevada do TJSP na hierarquia das instituições públicas, garantindo seu poder profissional e deferência social. Para tanto, precisaria preservar a capacidade de recrutamento com alta seletividade e construir a identificação desses membros com a magistratura.

Há vasta literatura sobre a participação das mulheres no mercado de trabalho e sua relação com os salários e rendimentos profissionais ${ }^{5}$. Em comum, as análises registram as mudanças estruturais e comportamentais na sociedade contemporânea impulsionando esse movimento, constatam a menor remuneração para o trabalho feminino e a desvalorização da atividade. Algumas explicações vêem a entrada desse contingente como conseqüência do menor interesse masculino dificultando o recrutamento dos 'melhores', que vão competir por posições mais vantajosas. Outras visões consideram esse ingresso como a causa das perdas profissionais, seja porque aumenta a oferta de serviços, formando o 'exército de reserva', seja porque as mulheres têm menos tempo para se dedicar à luta por essas conquistas devido aos cuidados com a família.

Independente do diagnóstico, os magistrados conhecem esses resultados, temem que ele se reproduza no TJSP e agem para controlar o impacto da feminização. A predominância de mulheres no judiciário francês ${ }^{6}$ é a referência negativa.

Um magistrado entrevistado referiu-se ao temor existente entre os pares no tribunal paulista de que o ingresso feminino na carreira tenha o

4 Entre esses aspectos estão a criação do Conselho Nacional de Justiça com atribuição de controle externo, e a súmula vinculante, na qual o entendimento do STF sobre a jurisprudência passa a ser obrigatório a todos os tribunais e juízes.

5 Ver Costa, Sorj, Bruschini e Hirata (2008); Hirata e Kergoat (2003); Giannini (2005), Schultz e Shaw (2003).

6 O corpo judiciário na França não se constitui em um Poder como no Brasil. É um segmento estatal vinculado ao Ministério da Justiça. $\mathrm{O}$ candidato ingressa na carreira como auditor de justiça. Há várias formas de ingresso com tipos diferentes de concurso, e o curso superior de Direito não é exigência, havendo possibilidades de ingresso para servidores públicos e para profissionais de outras áreas. Juiz e promotor são percursos que se cruzam, sendo possível irem de um para outro. Ambos são treinados na Escola Nacional da Magistratura. ( Fonte: http://www.direito2.com.br/tst/2004/nov/26/gelson_azevedo_fala_sobre_formacao_da_ magistratura_francesa) 
mesmo resultado: provocar a perda de prestígio social e os baixos salários da magistratura francesa. Ele comentou como a Escola Nacional da Magistratura francesa vê o processo de feminização do Judiciário lá.

Há uma experiência estrangeira, a França, que quer sempre orientar nossas escolas de magistratura. A França fala 'tome cuidado que a magistratura vai se tornar uma carreira feminina e a carreira feminina não tem capacidade de exigir aperfeiçoamento ou melhoria salarial, porque sempre o segundo salário é pra auxiliar a economia doméstica. Então a mulher se satisfaz com qualquer salário, e isso põe em risco as conquistas da magistratura brasileira. 'Não ponha muita mulher, porque a mulher não reivindica salário'. (desembargador 1)

A feminização da magistratura na França, segundo Boigeol (2003), foi um processo rápido. A primeira magistrada ingressou no Judiciário após a Segunda Guerra Mundial, época na qual se começou a registrar desinteresse pela carreira por parte dos filhos das famílias de elite. O crescimento na procura masculina pela magistratura veio dos filhos de famílias de classe média interiorana ou de servidores públicos. Em 1973, as juízas e promotoras eram $11.3 \%$, em 1982 chegavam a $28.5 \%$, em 1999 a $48.5 \%$ e em 2001 atingiram $50 \%$.

No judiciário francês, a partir de 1946, ocorreu inicialmente um processo de diferenciação de funções dos juízes, com mecanismos de segregação horizontal. As magistradas dedicavam-se às varas de família, infância e juventude. Esse tipo de segregação foi enfraquecido com o aumento do contingente feminino, e a atuação das juízas em diversas áreas. A diferenciação horizontal retraiu-se perante a diferenciação vertical, havendo mais homens que se apresentam para cargos e ocupam as posições do topo da hierarquia, mesmo tendo um número significativo de magistradas habilitadas a exercer funções de chefia, direção e representação (Boigeol, 2003, p. 411).

\section{Diferenças de gênero e sexualidade na carreira: abordagem que orienta o estudo}

A proposta deste estudo é buscar as formas como carreira, gênero e sexualidade se interseccionam constituindo discursos que reproduzem, contestam e ressignificam as diferenças. O gênero é abordado como uma construção cultural e social, uma categoria analítica que questiona a naturalização da dualidade sexual como constitutiva da essência fixa e imutável do ser, reconhecendo que a ênfase nas diferenças anatômicas foram essencializadas em contextos históricos e culturais específicos. Assim, Butler 
(2003) concebe o gênero como um gradiente que combina masculino e feminino com heterossexualidade e homossexualidade, sem oposições entre eles.

Quanto à diferença, a abordagem apóia-se em Brah (2006, p. 374): "se refere à variedade de maneiras como discursos específicos da diferença são constituídos, contestados, reproduzidos e ressignificados". Pode ou não ser interpretada como marcador fixo de hierarquia ou como relacional, contingente e variável. A perspectiva adotada aqui não singulariza uma leitura sobre a experiência dos magistrados e magistradas com a diferença na carreira, já que registramos formas plurais de se percebê-la na trajetória individual ou na instituição. Usamos a tipologia sugerida por Brah: diferença como experiência, diferença como relação social, diferença como subjetividade e diferença como identidade. Para a autora, "é útil distinguir a diferença como marcador de distintividade de nossas 'histórias' coletivas da diferença como experiência pessoal inscrevendo a biografia individual. Esses conjuntos de 'diferenças' se articulam constantemente, mas não podem ser 'lidas' uma a partir da outra" (Brah, 2006, p. 361).

Tal como conceituada por Brah, os discursos sobre a diferença na magistratura não são homogêneos, revelando as formas como esta é constituída nas relações sociais e profissionais; como é contestada por juízes e juízas que querem apagar a diferença por meio da neutralidade da expertise; como é reproduzida em relatos que as naturalizam, relacionando-as a uma essência específica do masculino, do feminino e da sexualidade; como é ressignificada, com os pares negociando as classificações sobre a postura profissional e os sentidos de ser magistrado(a).

Para a autora, a diferença como experiência é aquela inscrita na biografia individual, e aparece como lugar de formação do sujeito, sendo ambos concebidos como processo. Desaparece a "noção de que essas categorias são entidades unificadas, fixas e já existentes, e não modalidades de múltipla localidade, continuamente marcadas por práticas culturais e políticas cotidianas" (Brah, 2006, p. 361). O sujeito da experiência não é um ser pronto a quem as experiências acontecem. A diferença como experiência porta as contradições da subjetividade e da identidade. Assim, a experiência de uma mulher negra é partilhada como identidade racial, em comunidade e a experiência de gênero como subjetividade naturalizada na dominação.

A diferença como relação social se refere à forma como ela é constituída por discursos sistemáticos de contingência, sejam eles econômicos, políticos, culturais e pelas práticas institucionais. Um grupo articula esta diferença ao narrar as experiências históricas coletivas como um passado comum, tal como o legado da escravidão. Elas produzem as condições para as identidades 
coletivas, para os discursos compartilhados, mas não precisam se concretizar em comunidade.

A diferença como subjetividade é percebida como interioridade, mas o sujeito em processo é constituído em e através da experiência 'interior' e 'exterior'. Essa formação da subjetividade é ao mesmo tempo social e subjetiva, "donde o sujeito é entendido como descentrado e heterogêneo em suas qualidades e dinâmicas. A subjetividade então não é unificada nem fixada, mas fragmentada, constantemente em processo" (Brah, 2006, p. 368).

Na diferença como identidade, "a identidade pode ser entendida como o próprio processo pelo qual a multiplicidade, contradição e instabilidade da subjetividade é significada como tendo coerência, continuidade, estabilidade; como tendo um núcleo - um núcleo em constante mudança, mas de qualquer maneira um núcleo - que a qualquer momento é enunciado como o "eu" (Brah, 2006, p. 371). Para a autora, é problemático falar da identidade como existente e constituída se ela é processo, sendo mais apropriado referir à identificação. A identidade que é proclamada é uma re-feitura, uma construção, a identidade coletiva específica é um processo político por oposição à identidade como processo na e da subjetividade.

A identificação com a carreira e as formas de articular a diferença na magistratura é construída como processo neste trabalho. Partimos das mudanças no contexto interno e externo do TJSP, vinculando o impacto mútuo da reforma do Judiciário e da heterogeneidade da composição social da magistratura. Destacamos a centralidade que o tribunal procura atribuir à postura profissional com as modificações no processo de seleção e recrutamento. Registramos as negociações de significados em torno da corporalidade e os enfrentamentos discursivos sobre a diferença, apresentando as formas como ela é concebida quanto ao gênero e a sexualidade.

\section{Heterogeneidade social e identificação com a carreira}

Várias pesquisas por amostragem foram realizadas, para se conhecer melhor os magistrados brasileiros e os caminhos para a democratização do Judiciário, no contexto de discussão da reforma. Três desses estudos abordaram a composição social dos magistrados, o de Sadek (1995), o de Viana et al. (1997) e o de Junqueira et al. (1997). Todos eles constataram a mudança no perfil social da magistratura, observando-se a heterogeneidade na composição social. Sadek (2006) realizou novo survey com os membros da Associação dos Magistrados Brasileiros, enfatizando em suas conclusões a ampliação dessas mudanças, em especial, a inexistência de homogeneidade no grupo, o predomínio de uma visão crítica ao desempenho do judiciário, e 
o crescimento da participação feminina na carreira (27\% de magistradas entre os profissionais ativos).

Neste artigo, pretendemos refinar a análise sobre como a magistratura lida com a mudança em sua composição interna, à luz da expansão do ingresso de mulheres na carreira, e a centralidade que a postura profissional ganha para buscar homogeneizar a diferença.

Entendemos que em um contexto de reforma, com um ambiente externo pressionando por mudanças e com um ambiente interno mais heterogêneo, o tribunal buscou estratégias para manter sua alta posição social em vez de experimentar queda no prestígio e na seletividade de seu recrutamento. A diversificação da origem social de seus membros passou a ser apresentado como o trunfo do profissionalismo do Judiciário, enfatizando o rigor da seleção por mérito, a remuneração elevada, as garantias de carreira e a independência judicial. A competitividade em termos de desempenho cresceu, tornando a vaga de juiz(a) muito cobiçada. O recrutamento deslocou-se da classe social para o saber especializado. $O$ foco na coesão centrou-se na identificação com a carreira, numa essência própria de 'ser magistrado(a)'. A eficácia simbólica que transforma a magistratura em corpo passa pela construção coletiva de qual é a postura que condiz com o pertencimento institucional, produzindo uma estetização do modelo de juiz(a), que dá concretude a algo abstrato, como ser vocacionado(a). Marcadores de diferenças como gênero, sexualidade, raça foram incorporados pelo tribunal, mas como identificações da esfera íntima, a diferença interiorizada como subjetividade. $\mathrm{O}$ "nós” exteriorizado é corporificado pela neutralidade do profissionalismo, que invisibiliza as especificidades. Ser magistrado(a) é experimentado como uma existência pública, em uma organização de elite: uma alta posição, que traz recompensas, como poder, autoridade, deferência e autonomia profissional, mas na visão do grupo, requer uma contenção das pulsões, um recato e um autocontrole maiores.

A neutralidade da expertise não é um saber abstrato descolado do corpo. Ela ganha forma física, na postura imparcial, no vestir, na conduta nas relações profissionais com os pares, os jurisdicionados, a mídia, mas também nas relações sociais mais amplas com os vizinhos, os conhecidos, a família. A vivência dessa forma de ser, desse estilo de vida promove o sentimento de pertencimento. A coesão da magistratura não é acrítica, de caráter ideológico ou de opinião, ela se expressa no corpo, ao encapsular na interioridade a diferença, recompensando esse custo emocional com o reconhecimento, o prestígio e o valor de ser magistrado(a). Os resultados alcançados nesse processo trazem realização, tornando os membros da carreira ativos promotores da disposição 
interiorizante ${ }^{7}$ da subjetividade e do apagamento da diferença como identidade do eu ou como identificação coletiva proclamada.

O depoimento de uma juíza criminal é ilustrativo da contestação da diferença, encapsulando-a na interioridade, como conceituado por Brah, na diferença como subjetividade.

Eu como mulher trabalho tanto quanto igual a um homem. Não me coloco, não acho que tem de ter diferença no tratamento, me comporto como qualquer juiz aqui, trabalho tanto quanto. Quando fiquei de licença gestante, eu tenho uma filha de 10 anos de idade, usufrui tão somente 4 meses, que na época era o prazo, voltei a trabalhar no quinto mês, minha filha tem 10 anos, é uma criança muito bem criada, amada, bem resolvida. Não acho que porque você é mulher, tem filhos, tem que ter alguma benesse, alguma diferenciação do homem. Você optou por uma carreira como essa, sabia desde o começo que a carreira não era comum e nem é igual aos outros, a sociedade exige em contrapartida a prestação jurisdicional, depois o Poder Judiciário não tem mais nada, ou o juiz se coloca frente à sociedade e diz o que é certo ou o que é errado.

Acho que quando você abraça a carreira (...), opta por ser juiz de Direito e o cargo é de juiz de Direito, nem existe cargo de juíza de Direito, o cargo é de juiz de Direito, você sabe os percalços que tem. Aí você não pode querer mudar um tratamento porque você é uma mulher. Dentro da própria magistratura, quando eu passei, há 20 anos atrás, era tudo muito diferente, o número de mulheres era bastante reduzidíssimo, reduzidíssimo, e as pessoas me perguntam: você sofreu algum preconceito? Não. (juíza 1)

O apagamento do gênero como diferença identitária é uma ação promovida por sujeitos - mulheres em carreiras tradicionalmente masculinas. Diferencia-se da invisibilidade da experiência, como conceituada por Scott (1999). Aqui não se trata do silêncio público negando visibilidade, nem de tornar histórico algo escondido da história pelos mecanismos repressivos da sexualidade estigmatizada. A experiência na profissão traz mais reconhecimento e valorização social, reforçando a identificação profissional perante o pertencimento a outra comunidade, como a de gênero. O depoimento acima promove o apagamento da diferença como relação social na carreira. É uma forma ativa como algumas dessas profissionais interpretam experiências da diferença com igualdade, contestando a reprodução da relação de dominação e sujeição pela sua negação, nuançando na prática profissional fronteiras tão

\footnotetext{
7 Ver Duarte (2004), sobre a disposição interiorizante ser um dos atributos da sexualidade moderna, debatida nas ciências sociais como a oposição entre o comportamento sexual (erotismo) e identidade sexual (sexualidade).
} 
sedimentadas na naturalização dos contrastes de gênero. Os enfrentamentos discursivos negando a diferença como relação social desigual na carreira, e a forma como lutam para o feminino não ser transportado como essência para o profissionalismo é outra maneira de experimentar o gênero. Reforçar o cargo no masculino (juiz de direito) em vez do feminino (juíza de Direito) prioriza o valor social da profissão protegendo-a de estereótipos negativos sobre a inserção do feminino no público e no trabalho.

A juíza 1 vive a diferença como subjetividade em vez da diferença como relação social ou como proclamação política da identidade coletiva. A subjetividade experimentada como identidade se distingue da interpretação que vê a negação da hierarquia de gênero na carreira como a legitimação feminina da violência simbólica, praticada pela dominação masculina (Bourdieu, 1999). As juízas que contestam a diferença e negociam os sentidos da igualdade na carreira embaralham as distinções consolidadas e desnorteiam classificações fixas, pensando as fronteiras de uma nova forma. Ao falar de um lugar híbrido de enunciação (juiz mulher) põem em questão pretensões de universalidade explicativa.

\section{Postura e coesão da magistratura}

A coesão nos grupos profissionais é construída a partir da alteridade com os leigos. O coleguismo é a forma como os experts partilham os riscos de cometerem erros ou falharem nas decisões, dentro de uma especialização complexa que monopolizam. Em comum, os colegas entendem que só os pares podem definir o que é um fracasso ou um erro profissional (Hughes, 1984, p.316-325). É uma integração baseada na forma colegiada da autoridade do especialista, que em Weber é um tipo de dominação legal (Walters, 1989), uma ação social que se apóia numa união de interesses racionalmente motivados, em contraste com uma ação social que repousa no sentimento subjetivo de pertencer ao mesmo grupo. "A grande maioria das relações sociais, porém, tem caráter, em parte, comunitário e, em parte, associativo" (Weber, 2000, p. 25). A coesão profissional analisada neste estudo é concebida produzindo solidariedade orgânica, que para Durkheim (1978, p. 83) distingue-se da solidariedade mecânica, porque supõe que os indivíduos sejam diferentes uns dos outros, que tenham uma esfera própria de ação e uma personalidade, em vez de se parecerem e terem a personalidade individual absorvida pela personalidade coletiva.

Outro aspecto das ocupações de nível superior que caracteriza a concepção deste estudo sobre a coesão da magistratura é que elas fazem parte de um sistema de profissões (Abbott, 1988) movido pelas competições. Esta 
dinâmica marca as relações de coleguismo que são reguladas pelo código de ética profissional. O padrão desses laços é o da competição nas relações horizontais entre pares, havendo dominação e sujeição quando essas relações são hierarquizadas. Assim, há conflitos entre a primeira instância e a segunda instância e competições entre colegas por comissões, funções, vagas, posições, representações.

Os magistrados estão inseridos na dinâmica competitiva do sistema das profissões, vivenciam cotidianamente as disputas concorrenciais, as lutas por interesses específicos que caracterizam essas relações, mesmo que a partir de uma posição de poder. Em contrapartida, se concebem como distintos, como vocacionados, investidos de soberania do cargo, membros do corpo da magistratura. É a postura que dá concretude a essa passagem do profano para o sagrado, do interesse específico para o discurso do bem comum.

Sinhoretto (2005) analisa a corporalidade dos operadores jurídicos atuando na periferia de São Paulo, observando os ritos de administração da justiça nos CIC's - Centros de Integração da Cidadania, acompanhando as audiências, a sala de espera e os atendimentos. Segundo ela, os idealizadores do CIC tinham como projeto uma interação cotidiana mais simples entre operadores e usuários, sem um ritual judicial rígido e hierarquizado, mas o encontrado foi uma corporalidade destacadamente homogênea em relação aos de fora, embora internamente atravessada por hierarquias de gênero e de posição na carreira.

A autora parte da concepção de Foucault (1991) sobre o corpo, sendo este atravessado e constituído pelo poder, "com efeitos negativos de interdição, mas sobretudo efeitos positivos, criadores de sujeitos, efeitos de classificação, hierarquização, regulação e normalização" (Sinhoreto, 2005, p. 145). Ela articula também o conceito de Butler (2003) sobre o corpo no qual o gênero que ele expressa não é uma essência, mas o resultado de atos e gestos performáticos, sendo o efeito de discursos regulativos que criam identidades normalizadas; a performance fabrica a identidade corporal que é imitada ou parodiada tomando como referência o mito da feminilidade, da masculinidade.

A partir do trabalho de campo, sintetizamos referências que constroem um tipo ideal de postura dos(as) magistrados(as). Ele passa pelo recato, a apresentação pessoal discreta para não comprometer a credibilidade do cargo. A vestimenta pode ser moderna ou sóbria, mas tem de ter uma aparência de respeitabilidade, sem excessos de ostentação. O perfil tem de ser centrado, de serenidade, que passe confiança, a conduta precisa ser compatível com a dignidade do cargo não se expondo a situações públicas que a comprometa, 
Critica-se a 'juizite', a prepotência no trato com funcionários e outros operadores da Justiça, demandando também um comportamento que não destoe dos valores predominantes na comarca onde atua. Inclui-se, recentemente, o esforço para manter em dia o serviço, devido ao grande volume de trabalho e as pressões das metas de produtividade.

Embora seja consensual aos magistrados que há uma postura própria ao grupo, seu significado é mutável e renegociado no exercício capilar do poder no interior da magistratura. A concepção de analítica do poder de Foucault permite captar como esse conteúdo é modificado. Segundo esse autor, o poder é um feixe aberto, mais ou menos coordenado ( e mal coordenado) de relações. Não emana de um centro, nem de um modelo legal, mas está onipresente em toda a parte, circulando em redes, de modo capilar. Não é detido por um grupo (os dominantes) que alija os dominados. Em vez disso, para ele, uma relação de poder é um enfrentamento perpétuo ${ }^{8}$.

A negociação de significados se manifesta na forma como as palavras que compõem o modelo aceito de juiz são interpretadas. Assim, a ostentação que os magistrados atribuem aos sócios das principais sociedades de advogados, quando transferida para a magistratura varia bastante de conteúdo. Para uns, o relógio fino, a bolsa de grife e o carro caro são sinais de ostentação. Para outros, ostentar é andar de helicóptero.

Neste sentido, o poder de definir o que é a postura do magistrado não está centrado na cúpula do tribunal, mas exercido, apropriado, produzido nas relações com o ambiente interno e o ambiente externo, em um enfrentamento perpétuo para gerar dominação e sujeição.

Em 1994, com o crescimento do debate público sobre a reforma do Judiciário, e ocasião de ampliação no recrutamento e na heterogeneidade da composição da magistratura paulista, as forças tradicionais da cúpula do tribunal sentiram o impacto das mudanças na circulação do poder para produzir a corporalidade do grupo e reagiram às alterações na aparência. $\mathrm{O}$ uso da toga tornou-se obrigatório para conter a liberalidade dos trajes usados nos fóruns. Tal medida foi vista como uma tentativa de disciplinar as vestes femininas. $\mathrm{Na}$ ocasião, a proporção de mulheres no TJSP era inferior a $10 \%$.

A heterogeneidade da composição social da magistratura é acompanhada de negociações de sentido sobre o que é a postura e o decoro apropriados, conduta que não se isola dos valores predominantes na sociedade. Assim, em 2000, quando tinham 628 magistradas e um volume expressivo de servidoras

\footnotetext{
8 Sobre a analítica do poder, ver Maia (1995).
} 
do judiciário, a proibição das mulheres usarem calças compridas nas salas de julgamento e nas dependências do judiciário caiu.

O rigor das vestes sóbrias já não estava sendo praticado da mesma forma, perdendo eficácia simbólica para a produção cultural e política dos corpos. Em 2010, o judiciário paulista tinha mil vagas a mais do que as existentes em 1993 (1372); a segunda instância havia crescido de 132 para 360 desembargadores, recrutando mais juízes para o tribunal; as magistradas totalizam 745 no TJSP. Era inevitável que o modo capilar de enfrentamento das relações de poder se refletisse na postura profissional da magistratura paulista. A questão da conduta alimenta enfrentamentos perpétuos nas relações de poder internas à instituição.

Com a aprovação da reforma do Judiciário, os tribunais de alçada foram extintos e seus juízes incorporados à segunda instância. Em 2005, o total de vagas de desembargadores dá um salto, mudança que teve impacto no judiciário paulista como um todo, inclusive na interpretação da experiência de ser magistrado(a). A corporalidade da magistratura é foco de embates para manter sua eficácia simbólica ou para ser deslocada desse lugar. Ela não é fixa e seu conteúdo está sujeito a ressignificações relacionadas às experiências individuais e coletivas da diferença.

Há fatores internos à trajetória da carreira que mudam a interpretação sobre a experiência profissional, refletindo-se na postura. No início, as juízas e os juízes substitutos têm que enfrentar um conjunto de decisões e de rotinas que são novas. Vários deles aparentam também serem muito jovens, dependendo mais da corporalidade para obterem o reconhecimento de que são um poder, quando se vêem em lutas concorrenciais na tentativa de deslegitimá-los. Assim, agem de forma mais dura, vista como brava, para lidar com a hostilidade, o que é reavaliado com o amadurecimento profissional. Embora ocorra com juízes, são mais freqüentes entre as juízas as agruras para se fazerem respeitar pelos advogados e jurisdicionados nesse início de carreira, especialmente nas comarcas do interior. Quando o acompanhamento e a avaliação dos superiores se concretizam positivamente, e os substitutos alcançam o vitaliciamento, a experiência se modifica e a subjetividade também. Acumula-se segurança em sentenciar, em lidar com os pares, os operadores do direito, os funcionários e os jurisdicionados. A rigidez corporificada pode experimentar outras performances para a diferença apagada como identidade.

Várias juízas relacionaram a experiência da diferença de gênero como uma relação social de conflito no início da carreira, com os "de fora" da magistratura. O depoimento abaixo relata como uma juíza viveu e foi modificando esse sentimento. 
Não parece, mas eu sou considerada bastante brava. Tem advogados - mas é bom porque as pessoas já chegam, quando você tem fama de brava as pessoas já chegam para você com maior cuidado, não chegam chutando a porta, ainda assim eu vejo que acontece, passou a ser mais eventual, mais raro, mas de vez em quando você pega advogados chutando a porta. (...)

(...) A minha vida no trabalho era ficar na defensiva, e no final não precisava muito para eu estourar. Mas isso também é maturidade de você conseguir diferenciar, quando você precisa se defender e quando não precisa. Hoje, eu até brinco, um trabalho que eu não me reconheço, quando eu estava no começo de carreira eu era muito mais impaciente, justamente pela própria situação que eu vivia, hoje eu procuro enfrentar situações, antes de reagir na mesma moeda de agressividade eu procuro acalmar a situação e só em último caso que eu boto a pessoa para correr. (Juíza 2)

Outro fator interno à carreira que reforça o peso dado à postura para a distinção é a condição material do Judiciário discrepante do poder investido no magistrado(a). O espaço, as instalações na primeira instância em algumas comarcas e fóruns têm uma aparência que não evidencia a autoridade do posto, concentrando-a na corporalidade e no tablado. Tomando-se como referência as sociedades de advogados, as empresas que as contratam, os bancos, entre outras organizações nas quais os profissionais atuam, uma comarca sem recursos ou uma vara no Fórum João Mendes, no centro de São Paulo, criam o mesmo estranhamento: a ausência de símbolos de status no local. A vara, algumas vezes, é uma sala pouco mobiliada, na qual a pessoa ingressa e já se depara com o magistrado(a). Juízas comentaram que foram confundidas com servidores quando estavam trabalhando em sua vara.

\section{Recrutamento e seleção}

A cúpula da magistratura procurou manter elevado o status da carreira, quando o recrutamento de seus membros se diversificou intensificando a competitividade e seletividade dos concursos de ingresso. A passagem abaixo, relatada por um desembargador, faz o contraste entre os concursos na época em que ele ingressou (início dos anos 1980) e aqueles realizados atualmente.

Hoje em dia o concurso está uma exigência muito grande, porque se você pegar o edital ele é monstruoso, tem um número enorme de matérias diferentes, de leis. Enfim, o direito está hoje cada vez mais complexo (...). Então, o volume de conhecimento hoje pra ter sucesso num concurso, exige muito estudo, muito preparo, os concursos são muito exigentes principalmente na parte teórica. Se você não tiver oportunidade pra se dedicar, pra estudar, pra ficar 
focado naquele projeto, então...você não vai ter êxito. E as mulheres eu sinto que são mais organizadas, elas já, algumas já focadas nisso, já começam a se preparar já no tempo do banco escolar... $\mathrm{Na}$ faculdade ela já está com aquela vontade e o homem, às vezes, até a gente vê na faculdade, demora pra amadurecer e vai lá mais pra, às vezes, fazer um social, pra se envolver lá em atividades de esporte e tal... (desembargador 2 )

Embora a seletividade dos concursos seja reconhecida, ela não é igualmente avaliada como uma forma adequada para medir desempenho e escolher os melhores membros para a magistratura. Há desembargadores que defendem um processo de recrutamento e de administração do tribunal profissionalizado, em vez de ser atribuição da cúpula. A experiência de delegar o processo de seleção para empresas especializadas foi suspensa, reativandose a forma tradicional de nomeação de uma banca, com os desembargadores responsáveis pela preparação dos concursos afastando-se das funções rotineiras do TJSP.

Observamos também nas entrevistas uma variação nas opiniões sobre a diferença de gênero e seu impacto no recrutamento e seleção para a magistratura. Quem entende que a barreira de ingresso está superada toma como critério o montante de juízas que vêm sendo incorporadas à carreira ${ }^{9}$, as formas como a progressão se desenvolve e a renovação do tribunal, com ampliação do pleno e a aposentadoria dos "colegas que eram mais refratários à presença feminina na magistratura" (desembargador 2). Contrastam o presente do TJSP com o passado recente e identificam muitas mudanças. O concurso de 1980 que abriu o recrutamento aprovou apenas três juízas ${ }^{10}$, mas desde 1996, a lei estadual 9351 vedou a identificação dos candidatos nas provas escritas do concurso, impedindo a eliminação das mulheres ao descobrir o sexo pelo nome. Argumenta-se que o ingresso hoje é pelo desempenho no concurso e a progressão na carreira ocorre por antiguidade, já que não se definiu internamente o que seria o mérito e este critério não vem sendo usado para a promoção.

$\mathrm{Na}$ opinião de uma juíza entrevistada não há diferença entre homem e mulher na carreira.

Aqui na magistratura a promoção é uma questão de tempo, a não ser que você tenha algum problema gigantesco que o tribunal vede de alguma forma a sua inscrição na promoção. Se você tiver processo atrasado, pra você se inscrever pra promoção você tem que ter

\footnotetext{
9 As pesquisas de Junqueira (1998) e Barbalho (2008) também encontraram essa visão no discurso de várias juízas, a superação das desigualdades de gênero na carreira da magistratura.

10 Ver Melo, Nastari e Massula (2005).
} 
uma planilha zerada e uma certidão de que você não tem nenhum processo há mais de dez dias com você, o que hoje é muito difícil, mas se a pessoa sabe que está na época da promoção enfim, tira férias, trabalha em casa, resolve os atrasos, mas é basicamente isso, é tempo de carreira pra você se promover.

(...) Eu não vejo, sinceramente, eu não vejo nada que torne a carreira mais difícil pra mulher. (juíza 3)

A opinião contrária, que identifica o preconceito com as mulheres, foca nas redes de circulação de comentários no tribunal. Observa-se tanto as referências estigmatizadas sobre condutas impróprias à magistratura, bem como os estereótipos generificados da feminilidade a "arejar" a convivência institucional. Essa visão não se apóia na proporção de mulheres ingressando ou progredindo na carreira, mas nas informações de bastidor que emitem sinais ambivalentes: publicamente, há um empenho em ajustar a eficácia simbólica da corporalidade da magistratura, com as juízas contribuindo ativamente nisso, mas se afirma a ausência de tratamento desigual na carreira; no ambiente privado há a valorização dos atributos corporais femininos, e o temor que a feminização represente custos de desvalorização profissional.

(...) eu acho que é um preconceito, ainda existe preconceito com a mulher, eles acham sempre que a mulher só estudou pra ela passar no concurso, então ela é uma moça que não conhece a vida e ela vai ser alvo do primeiro malandro que aparecer, um advogadinho e infelizmente têm acontecido algumas coisas que mostram, que reforçam esse preconceito (...)

O Tribunal de Justiça ficou mais de 100 anos sem admitir mulher, então havia aquela restrição com a maternidade, 'é um profissional muito caro pra ficar afastado meses do trabalho, pagando sem trabalhar'. Outra coisa é achar que a mulher é vulnerável em termos de ser enganada, 'qualquer agradinho você canta uma mulher ela já fica toda derretida', sabe, isso ainda é muito presente. (desembargador 1)

Objetivamente, o recrutamento do TJSP diversificou a origem social e o gênero mais do que a raça/etnia e a sexualidade dos magistrados. Sendo a sexualidade interpretada como uma questão de foro íntimo, encapsulado na interioridade, não há informação disponível que possa ser mensurada. Quanto à raça e o ingresso de negros, o survey coordenado por Sadek (2006) para a magistratura brasileira na ativa, encontrou $0.9 \%$ de magistrados se declarando negro, $12.4 \%$ pardos, $85,7 \%$ de brancos, $1,0 \%$ amarelo e $0.1 \%$ vermelho. Indagados especificamente sobre juízes negros, os entrevistados consideram que há um número muito limitado na magistratura, mas não vinculam isso a 
preconceito no processo de entrevista. Atribuem à peneira social que elimina os negros dos cursos superiores competitivos e da preparação para o concurso, prejudicando as chances de aprovação nas primeiras fases da seleção. Olham essa diferença na perspectiva da relação social, da produção das desigualdades e dos discursos sobre ela e não de um apagamento da diferença como identidade.

Ao contrário da ambivalência registrada nos sinais emitidos sobre o feminino e a feminilidade, sobre a sexualidade ecoa a mesma mensagem: o tribunal é conservador, as bancas obtêm informações sobre os candidatos e não aprovariam se houvesse referência a uma postura que torna visível a diferença como identidade proclamada ou como comportamento destoante. Mencionase o conhecimento de poucos colegas gays e é ainda menor a referência a colegas lésbicas. Obtido o ingresso na carreira, a discrição é o caminho, já que a conduta e a baixa produtividade seriam os aspectos que deixariam um juiz ou uma juíza vulnerável na magistratura.

As passagens abaixo foram extraídas de duas entrevistas que reforçando ou não a posição do tribunal reconhecem a discriminação no processo de seleção.

Então veja, às vezes a banca pesquisa essas coisas eventuais, vamos imaginar que alguém, que as pessoas falem desvio, vai (...).

A sociedade traz um certo preconceito em qualquer situação, mas eu acho assim, se houver uma discrição, a pessoa não deixar que, de alguma maneira, isso contamine a sua postura e tudo mais e seja discriminado, porque a discriminação eu acho que ocorre mais por conta das atitudes, por conta da postura. O sujeito pode ser hetero ou homossexual, se não tiver uma postura adequada, ele vai denegrir a imagem da magistratura e vai ter que ser de alguma maneira sancionado...(desembargador 2)

É, sabe uma coisa, nós tivemos recentemente um desembargador que ele foi apanhado mantendo relações com a escrevente dele no gabinete, todo mundo 'tigrão, tigrão, tigrão', e ficou sabe..., condicionado, ainda todo mundo fala 'ah que beleza, ah tal' e achar que o rapaz por ser homossexual, ele seria, ele transigiria com a..., eu acho isso um pouco, uma demasia, então esse eu acho um preconceito muito mais esquisito e essa, e há muita gente que traz durante, na banca, gente que traz informações 'ah não sei, o cara nunca está com mulher', essas coisas. (desembargador 1)

Quanto à sexualidade, a diferença é invisibilizada, centrando a identidade na profissão. Há algum enfrentamento discursivo entre a visão da diferença contida na subjetividade e a possibilidade de ela vir a ser experimentada como identidade, que está sinalizada na desqualificação feita sobre o comportamento 
viril e sua aceitação pelos pares. As experiências das diferenças de gênero e de sexualidade na magistratura se distinguem, mas em ambas a interpretação dominante é mantê-las na subjetividade, seja pelo apagamento ativo promovido pelos pares, seja pelo controle do tribunal. A identidade profissional predomina sobre as outras, que estão presentes de forma mais descentrada e fragmentada.

Ser magistrado é uma reconstrução do self que repõe o status social negado à mulher e ao homossexual na sociedade e traz recompensas. Rumens e Kerfoot (2009) analisaram homens gays no trabalho em organizações receptivas (gay-friendly). Eles sugerem que mesmo nesses ambientes, os homens gays atuam sobre o self para se identificarem como profissionais, vivendo empoderamento. Assim, não deixam de ser afetados pelas normas que tratam a sexualidade e o profissionalismo como pólos opostos. Os autores tratam os dilemas sobre quais identificações serão assumidas abertamente como dilemas da identidade profissional.

Outro aspecto que merece atenção na relação entre profissionalismo e gênero diz respeito às juízas que vivem a experiência da maternidade e dos cuidados com a família. É destacado no enfoque que concebe da divisão sexual do trabalho ${ }^{11}$ nas profissões jurídicas (Junqueira, 1998; Schultz e Shaw, 2003, Barbalho, 2008, Bonelli, Cunha, Oliveira e Silveira, 2008) o contraste entre o mercado privado da advocacia e as carreiras públicas, em termos de maior e menor hostilidade à progressão das profissionais. A maternidade é vista como risco de interrupção da carreira para priorizar os cuidados com a família, em vez da dedicação tempo integral ao trabalho. Feuvre e Lapeyere (2005) conceituaram o script ${ }^{12}$ sexuado de progressão na carreira. Ele pressupõe que homens são competentes e mulheres precisam provar sua capacidade. Pressupõe também que a mulher não tem disponibilidade total para o trabalho, atribuindo apenas a elas a conciliação da vida familiar e privada. Homens ficam dispensados dessa conciliação atendendo ao perfil das firmas de dedicação integral à profissão.

As carreiras jurídicas públicas seriam mais flexíveis às demandas da dupla jornada de trabalho, já que parte do volume de serviço poderia ser feito em casa. A lógica de mercado embutida no script sexuado não daria a

11 As abordagens sobre divisão sexual do trabalho estão retomando o uso do conceito de mulher em substituição ao de gênero, demarcando divergências com concepções como as de Butler, que diluem as fronteiras entre masculino e feminino, homossexualidade e heterossexualidade. Há um uso político do vínculo entre gênero, mulher e feminismo, que essencializa, mas produz identidades coletivas.

12 Alguns trabalhos optaram por traduzir o termo para roteiro profissional, como o livro de Costa, Sorj, Bruschini e Hirata (2008). 
tônica nas relações profissionais: a competência das juízas estaria estabelecida pelo concurso público, a flexibilidade de realizar parte do trabalho em casa facilitaria a dedicação. O ideal buscado por essas juízas, da dupla realização como profissional e mãe, se constitui em identidades que se tensionam e produzem uma terceira jornada de trabalho (Hochschild, 2003). Segundo essa autora, trata-se dos custos emocionais dos sentimentos de culpa pela reduzida atenção aos filhos, pelas dificuldades de dar conta da pilha de processos com a devida atenção às sentenças, de estudar, e pelas pressões que isso coloca para modificar as atribuições tradicionais da mãe e do pai na família.

O depoimento abaixo, extraído de Barbalho (2008, p. 138-139), ilustra como essa experiência de gênero distingue-se da vivida pelas juízas precedentes, sendo a maternidade $\mathrm{o}$ aspecto marcante da diferença.

(...) Tenho três filhos, uma de dez, uma de cinco, e um bebê de um ano. É muito louco, isso aí eu conseguir dar conta, eu agradeço a Deus todos os dias porque eu tenho DISPOSIÇÃO. Porque você tem que ter disposição fora do comum para conseguir suprir a casa, as crianças, o trabalho, olhar para você, o casamento, mas chega uma hora que você pode ter um milhão de problemas em casa, mas você tem que estar trabalhando, não tem jeito. Meu marido é dentista, mas me compreende bem, me acompanha, me ajuda no que eu preciso, ele compreende muito. Óbvio que $90 \%$ dos encargos ficam comigo, mas isso aí, sei lá, eu acho que é da própria natureza da mulher. (...) Então, eu acho que essa nossa capacidade de acumular atribuições, se desdobrar e ter o primeiro, segundo e terceiro turno, que não é mentira mesmo, essa coisa traz facilidade para o nosso trabalho. E o homem tem muito mais tempo para ele, isso é inegável, por mais que a tendência hoje seja de um pai mais participativo, colaborador, mas está longe de você igualar as funções dentro de casa (...)

(...) Muito mais disponibilidade. Eu não tenho dúvidas, eu tenho exemplos assim, amigos, eles são dois juízes, marido e mulher, têm dois filhos, ele está no doutorado, ela não, nunca mais estudou desde que ela teve filho. Então este é ainda um problema para nós, a menos que você renegue, eu não vou ser a mãe, ou você terceirize a criação de seus filhos, senão você não consegue. Eu consigo trabalhar, cuidar da minha casa e dos meus filhos, mas eu não consigo estudar, por exemplo, eu quero fazer o meu mestrado, e eu sei que só vou conseguir fazer quando as crianças quando as crianças estiverem maiores, (...)"

Nessa narrativa sobressai como a maternidade reforça o essencialismo de gênero e desloca a identidade profissional do domínio que exerce sobre outras identidades coletivas, apagando-as parcialmente, como vimos em outras entrevistas. $\mathrm{O}$ self descentrado, fragmentado e em constante processo transita 
pela diferença, e a interpreta como experiência, como relação social, como subjetividade e como identidade. São diferenças que não estão encapsuladas, não são apagadas, mas o gênero no discurso dessa juíza, mesmo que ressignificando a opressão, traz o marcador da hierarquia, da sujeição. Ela experimenta a diferença como identidade, podendo enfrentar discursivamente, contestar a subordinação e construir projetos identitários pelos quais está, ativamente, procurando realizá-los como multiplicidade de posições de sujeitos.

No trabalho de campo ouvimos experiências diferentes de gênero, que se referem a situações sociais distintas. Por um lado, há entre as juízas uma ênfase em negar a desigualdade de gênero na carreira, um apagamento ativo da diferença como relação social construída como assujeitada, mostrando a vivência da diferença como variável, e manuseando a subjetividade. Tal como abordamos na invisibilidade da sexualidade, a identificação profissional reconstrói o self da magistrada repondo o status social que a sociedade nega ao feminino, e é desse novo lugar que experimenta a si mesma como 'eu'. A maternidade potencializa o essencialismo e junto com ele a diferença como hierarquia, como sujeição em uma relação de dominação, que vincula a natureza da mulher com a capacidade de acumular atribuições, múltiplas jornada. Por outro lado, nas entrevistas com os magistrados, registramos os dois tipos de discurso, o do apagamento da diferença de gênero na carreira e o da persistência da desigualdade nas formas de julgar comportamentos, produzir e repetir estereótipos. Finalmente, a diferença como relação social de assujeitamento também aparece nos discursos que constroem o script sexuado da magistratura, - no lugar do questionamento da competência da advogada, pairam as dúvidas sobre a produtividade da juíza, como se elas precisassem mostrar que são tão produtivas quanto os juízes, que se dedicam integralmente à carreira, que se capacitam e atualizam, e que dão conta do recado.

\section{Conclusões}

$\mathrm{O}$ artigo procurou relacionar os impactos mútuos do profissionalismo e da diferença de gênero na carreira da magistratura, em vez da visão de que eles se constituem em dois pólos opostos. Para fazê-lo, partiu do contexto de discussão e aprovação da reforma do Judiciário, ocasião em que se ampliou a composição TJSP, ocorrendo um deslocamento das elites tradicionais do tribunal, com a renovação da segunda instância.

Acompanhou as formas como o tribunal reagiu a essa diversificação com estratégias para manter-se como uma carreira pública de elite. Assim, em contraste com a tradicional homogeneidade do recrutamento nas profissões 
jurídicas e nas famílias de berço, o recrutamento socialmente heterogêneo foi transformado em evidência do critério do mérito, da seleção dos mais capacitados, conseguindo preservar as prerrogativas que mantiveram a carreira muito cobiçada. Outra estratégia apontada foi a eficácia simbólica que a postura profissional alcançou para dar coesão à magistratura, com a negociação de sentidos sobre ser magistrado(a). A análise mostrou os limites e as possibilidades dessa construção através do conceito de diferença e das formas como ela é experimentada na carreira, no gênero e na sexualidade.

Definiu-se a coesão profissional em contraste com o mundo leigo, mas situada no âmbito das competições do sistema das profissões, como solidariedade orgânica, com espaço para a heterogeneidade. Assim, as negociações e enfrentamentos em torno dos significados da postura dos magistrados(as) no interior do grupo são apresentados, articulados às maneiras de se interpretar a diferença. Predominam as percepções da diferenças de gênero e de sexualidade como parte da interioridade, da subjetividade, procurando dar visibilidade à neutralidade do profissionalismo, pela corporalidade. Mas essas interpretações da diferença se deparam com outras, que vocalizam a diferença como identidade, como relação social e como experiência, tanto na primeira quanto na segunda instância.

Tal como já observado em outros estudos sobre as juízas, encontramse narrativas que negam a persistência das diferenças de gênero na carreira. Entendemos esta visão como uma forma de atuar sobre o processo de formação da subjetividade e modelar a identificação profissional. Ativamente, elas afirmam o apagamento das diferenças, a partir da experiência da conquista de posições de poder, elevando o status social que a sociedade nega à mulher. $\mathrm{O}$ enfrentamento discursivo ocorre entre o apagamento e a visibilidade do gênero, seja ao apontar o preconceito ou ao essencializar o gênero, atribuindo às magistradas as marcas do feminino que fragilizam a carreira. Quanto à sexualidade, a invisibilidade é a forma hegemônica de tribunal lidar com essa diferença, não havendo ambivalência nos sinais emitidos sobre ela como registramos para o gênero.

Como a identificação do self é modificada pela ativa reconstrução, a visão essencialista do magistrado(a) vocacionado, centrado, está sujeita à mudança. Embora o modelo de postura mantenha eficácia simbólica, os pares travam lutas e negociam sentidos para modelá-la ao novo contexto interno e externo à instituição. Marcadores de diferença que hoje são mantidos na interioridade, como parte da esfera íntima, se interseccionam com a neutralidade do profissionalismo, podendo ser experimentados como identidade pessoal e coletiva deslocando a profissão dessa posição, e da forma como se corporifica 
na postura. O poder e o prestígio de ser autoridade judicial é a força que mantém a identidade profissional no núcleo da identidade do magistrado.

Se o status social da carreira é tão impactante sobre a diferença, ele também dá mais poder para se alterar padrões tradicionais de gênero, diluindo as fronteiras entre masculino e feminino no projeto de vida desses profissionais. Se há mulheres na magistratura se debatendo com a dupla jornada de trabalho e homens isentando-se da conciliação dessas atribuições para dedicar-se integralmente à carreira, encontramos juízas e juízes que põem em prática um projeto de vida no qual a carreira é parte importante dele, é uma identidade em intersecção com outras, não sendo um todo fixo, unificado, permanente. Nesses casos, o descentramento da identidade profissional está em curso, em enfrentamento com o modelo predominante.

\section{Referências}

ABBOTT, Andrew. The system of profession. Chicago: The University of Chicago Press, 1988.

BARBALHO, Rennê Martins. A feminização das carreiras jurídicas e seus reflexos no profissionalismo. Tese (Doutorado) - Programa de Pós-Graduação em Sociologia, UFSCar, São Carlos, 2008.

BONELLI, Maria da Gloria; CUNHA, Luciana Gross; OLIVEIRA, Fabiana Luci; SILVEIRA, Maria Natália B. Profissionalização por gênero em escritórios paulistas de advocacia. Tempo Social, v. 20, n. 1, p. 265-290, 2008.

BOIGEOL, Anne. Male strategies in the face of the feminization of a profession: the case of the French Judiciary. In: SCHULTZ, Ulrike; SHAW, Gisela. Women in the world's legal professions. Oxford: Hart Publishing, 2003.

BOURDIEU, Pierre. A dominação masculina. Rio de Janeiro: Bertrand Brasil, 1999.

BRAH, Avtar. Diferença, diversidade e diferenciação. Cadernos Pagu, v. 26, p. 329-376, 2006.

BUTLER, Judith. Problemas de gênero: feminismo e subversão de identidade. Rio de Janeiro: Civilização Brasileira, 2003.

CARDIA, Nancy; ADORNO, Sergio; PINHEIRO, Paulo Sergio (coord.). LOCHE, Adriana Alves; SCHRITZMEYER, Ana Lúcia Pastore; NEME, Cristina; JUSTO, Marcelo. Proposta de Intervenção na Formação de Profissionais do Judiciário, do Ministério Público e da Polícia no Estado de São Paulo, NEV, USP (1998).

COSTA, Albertina; SORJ, Bila; BRUSCHINI, Cristina; HIRATA, Helena. Mercado de trabalho e gênero: comparações internacionais. Rio de Janeiro: Ed. FGV, 2008.

DUARTE, Luiz Fernando Dias. A sexualidade nas ciências sociais: Leitura crítica das convenções. In: PISCITELLI, Adriana; GREGORI, Maria Filomena; CARRARA, Sergio. Sexualidade e saberes: convenções e fronteiras. Rio de Janeiro: Garamond, 2004.

FEUVRE, Nicky Le; LAPEYERE, Nathalie. Les "scripts sexués" de carrière dans lesprofessions juridiques en France. In: Giannini, Mirella (org.). The feminization 
of the professions. Thematic issue. Knowledge, Work \& Society, Paris, n. 1, v. 3, p. 101-126, 2005.

FOUCAULT, Michel. Vigiar e punir. Petrópolis: Vozes, 1991.

GIANNINI, Mirella (org.). The feminization of the professions, Thematic issue. Knowledge, Work \& Society, Paris, n. 1, v. 3, 2005.

HIRATA, Helena; KERGOAT, Danièle. A divisão sexual do trabalho revisitada. In: MARUANI, Margareth; HIRATA, Helena (orgs.). As novas fronteiras da desigualdade: homens e mulheres no mercado de trabalho. São Paulo: Senac, 2003.

HOCHSCHILD, Arlie R. The commercialization of intimate life: notes from home and work. Berkeley: The University of California Press, 2003.

HUGHES, Everett C. The sociological eye: selected papers. New Brunswick/New Jersey: Transaction Books, 1984.

JUNQUEIRA, Eliane B.; VIEIRA, José Ribas; FONSECA, Maria Guadalupe P. Juizes: retrato em preto e branco. São Paulo: Letra Capital Editora, 1997.

JUNQUEIRA, Eliane B. A mulher juíza e a juíza mulher. In: BRUSCHINI, Cristina; BUARQUE DE HOLANDA, Heloísa. Horizontes plurais: novos estudos de gênero no Brasil. São Paulo: Fundação Carlos Chagas/Editora 34, 1998.

MAIA, Antonio C. Sobre a analítica do poder de Foucault. Tempo Social, v. 7, n. 1-2, p. 83-103, 1995.

MELO, Mônica; NASTARI, Marcelo; MASTURA, Leila. A participação da mulher na magistratura brasileira. Disponível em: $<$ http://www.maismulheresnopoderbrasil.com. br/pdf/Judiciario/A_Participacao_da_Mulher_na_Magistratura_Brasileira.pdf>, 2005. RODRIGUES, José Albertino (org.). Durkheim. São Paulo: Ática, 1978.

RUMEENS, Nick; KERFOOT, Deborah. Gay men at work: (Re)constructing the self as professional". Human Relations, v. 62, p. 763-786, 2009.

SADEK, Maria Tereza (org.). Uma introdução ao estudo da justiça. São Paulo: IDESP/Editora Sumaré, 1995.

SADEK, Maria Tereza. Magistrados: uma imagem em movimento. Rio de Janeiro: FGV Editora/FGV Direito Rio, 2006.

SCOTT, Joan. Gênero: uma categoria útil para a análise histórica. Revista de Educação e Realidade (Gênero e Mulheres), Porto Alegre, v. 16, n. 2, p. 5-22, 1999.

SCHULTZ, Ulrike; SHAW, Gisela (orgs.). Women in the world's legal professions. Oxford: Hart Publishing, 2003.

SINHORETTO, Jacqueline. Corpos do poder: operadores jurídicos na periferia de São Paulo. Sociologias, Porto Alegre, UFRGS, v. 6, p. 136-161, 2005.

VIANNA, Luiz Werneck; CARVALHO, Maria Alice R.; MELO, Manuel Palacios C.; BURGOS, Marcelo Baumann. Corpo e alma da magistratura brasileira. Rio de Janeiro: Revan/Iuperj, 1997.

WALTERS, Malcolm. Collegiality, burocratization and professionalization: a weberian analysis. American Journal of Sociology, v. 94, n. 5, p. 945-972, 1989.

WEBER, Max. Economia e sociedade. 3. ed. Brasília: Ed. UnB, 2000. v. 1. 